\title{
Characteristics of the pediatric patients diagnosed with SARS- CoV-2 infection in a Romanian children's hospital: a retrospective study
}

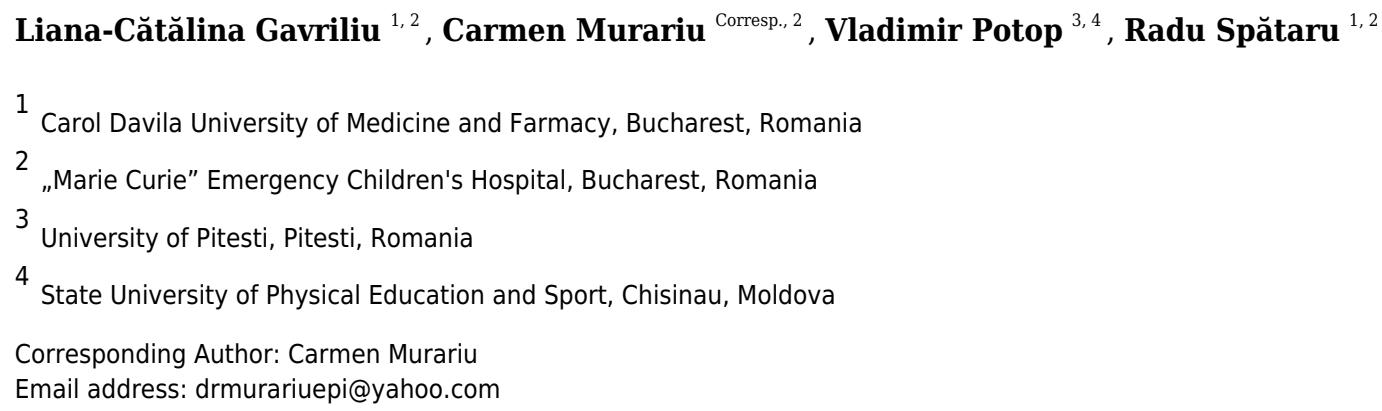

Background To date, information on COVID-19 pediatric patients is still sparse. We aimed to highlight the epidemiological and clinical data regarding SARS-CoV-2 infection in children and adolescents to improve the understanding of the disease in this age group and inform physicians during the ongoing COVID-19 pandemic. Methods We conducted a retrospective, observational study in "Marie Curie" Emergency Children's Hospital from Bucharest, Romania. We analyzed clinical and epidemiological characteristics of the patients confirmed with SARS-CoV-2 infection, between April 1, 2020-October 31, 2020. Results 172 patients aged 0-18 years were included, 79 (45.93\%) female and $93(54.07 \%)$ male patients. 28 (16.28\%) patients had co-morbidities (more often identified in asymptomatic group; $p<0.0001) .47(27.32 \%)$ had exposure to an identified source. 30 (17.44\%) patients were asymptomatic; 142 (85.56\%) had mild or moderate disease. The most frequent symptoms were: pyrexia (78.87\%), digestive symptoms (50\%), cough (40.14\%). Chest X-ray was performed in 50 patients and it was abnormal in half of them, all being symptomatic. About $2 / 3$ of the evaluated patients had normal leukocytes. The most common hematological change was lymphopenia; monocytes tended to be higher in symptomatic patients. About $40 \%$ of the patients were admitted; none required admission to ICU. No significant differences were found between symptomatic and asymptomatic patients regarding gender, age distribution, and exposure to a source. Conclusions All the patients had asymptomatic, mild or moderate disease. Patients with comorbidities, classically considered high risk patients, presented the same pattern of disease. 
2 Characteristics of the pediatric patients diagnosed 3 with SARS-CoV-2 infection in a Romanian children's

4 hospital: a retrospective study

5

6

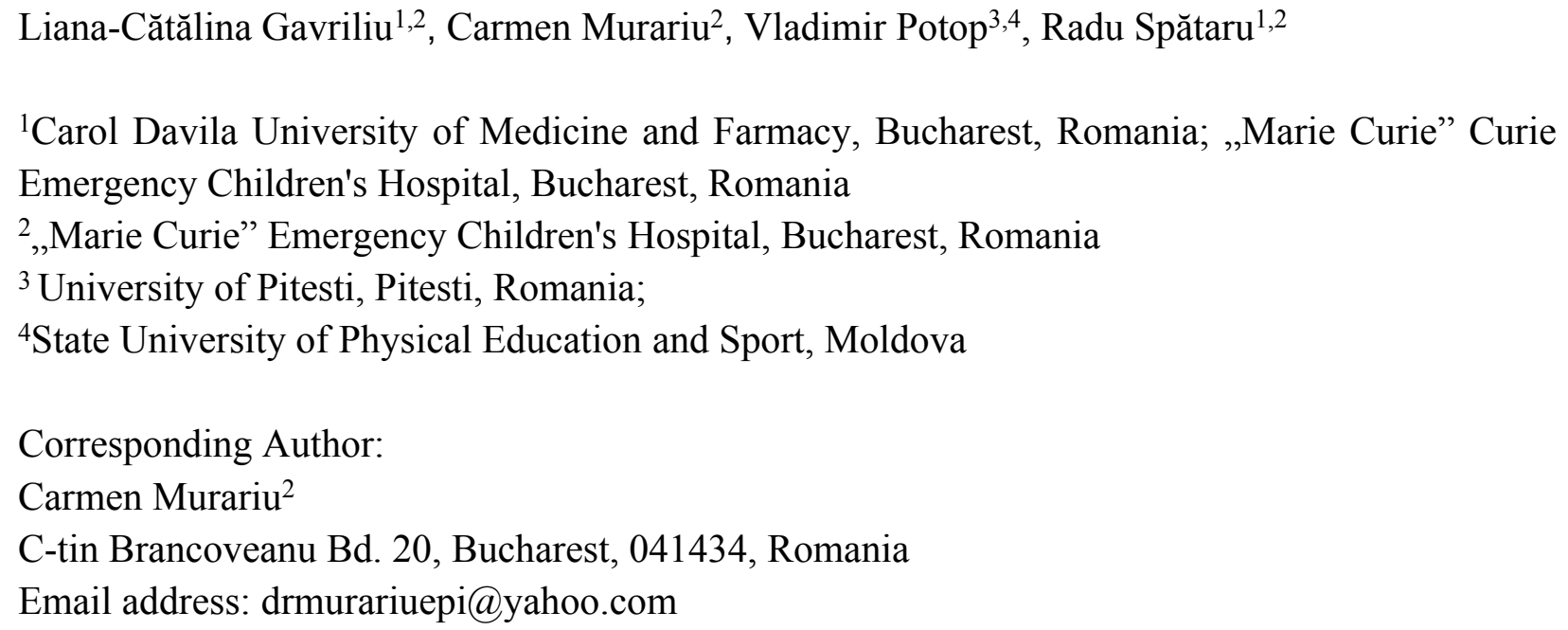

\section{Abstract}

\section{Background}

To date, information on COVID-19 pediatric patients is still sparse. We aimed to highlight the epidemiological and clinical data regarding SARS-CoV-2 infection in children and adolescents to improve the understanding of the disease in this age group and inform physicians during the ongoing COVID-19 pandemic.

\section{Methods}

We conducted a retrospective, observational study in "Marie Curie" Emergency Children's Hospital from Bucharest, Romania. We analyzed clinical and epidemiological characteristics of the patients confirmed with SARS-CoV-2 infection, between April 1, 2020-October 31, 2020.

\section{Results}

172 patients aged 0-18 years were included, 79 (45.93\%) female and 93 (54.07\%) male patients. $28(16.28 \%)$ patients had co-morbidities (more often identified in asymptomatic group; $p<$ 0.0001). $47(27.32 \%)$ had exposure to an identified source. 30 (17.44\%) patients were asymptomatic; $142(85.56 \%)$ had mild or moderate disease. The most frequent symptoms were: pyrexia $(78.87 \%)$, digestive symptoms $(50 \%)$, cough $(40.14 \%)$. Chest X-ray was performed in 50 patients and it was abnormal in half of them, all being symptomatic. About $2 / 3$ of the evaluated patients had normal leukocytes. The most common hematological change was lymphopenia; monocytes tended to be higher in symptomatic patients. About $40 \%$ of the patients 
39

40

41

42

43

44

45

46

47

48

49

50

51

52

53

54

55

56

57

58

59

60

61

62

63

64

65

66

67

68

69

70

71

72

73

74

75

76

77

were admitted; none required admission to ICU. No significant differences were found between symptomatic and asymptomatic patients regarding gender, age distribution, and exposure to a source.

\section{Conclusions}

All the patients had asymptomatic, mild or moderate disease. Patients with comorbidities, classically considered high risk patients, presented the same pattern of disease.

Introduction

Global spreading of the new coronavirus disease (COVID-19), caused 19, 44,888,869 cases confirmed all over the world, resulting in up to $11,78,475$ deaths globally, since late December 2019, when WHO was notified about an unusual outbreak of pneumonia in Wuhan, China, until October 30, 2020 (e.g. WHO, 2020a).

In Europe, the first cases of infections caused by the newly identified virus, SARS-CoV-2, were recorded on January 25, 2020 (e.g. WHO, 2020b) and spread rapidly; 11,062,715 cases and 285,135 deaths were reported by October 31, 2020 (e.g. WHO, 2020 c).

In Romania, the first case was reported on February 26, 2020(e.g. Rapid analysis of Romanian COVID-19 confirmed cases, 2020), 241,339 cases and 6,968 deaths being confirmed by the end of October 2020 (e.g. WHO, 2020 c).

Despite the large amount of available data regarding adult patients with SARS-CoV-2 infection, there are still limited data regarding SARS-CoV-2 infection in children. From what we know so far, compared with adults, COVID-19 in children is less frequent and less severe. There is a low prevalence of diagnosed children with SARS-CoV-2 all over the world. In United States (e.g. Bialek et al., 2020), less than $2 \%$ of the cases were reported in children, similar to the reports from Spain (e.g.Tagarro et al., 2020) or Italy (e.g. Livingston and Bucher, 2020). Other countries, with higher rates of community testing, found that only $4 \%$ of the cases were children (e.g.Williams et al., 2020).

In Romania, the pediatric population accounted for $6.55 \%$ (15,817 cases) of all the reported cases at the national level. 5,165 out of 15,817 cases (32.62\%) were confirmed in children up to 9 years old and 10,657 (67.38\%) were confirmed in children between 10-18 years old (e.g. Sava, 2020).

SARS-CoV-2 infection in children is also less severe than in adults, including patients traditionally considered to be at high risk of severe infections (e.g.Boulad et al., 2020). Although SARS-CoV-2 infection in most children is commonly asymptomatic or with mild symptoms, in some cases pediatric patients can develop severe disease, complications and require prolonged intensive care support (Lu et al., 2020; Riphagen et al., 2020). Moreover, a severe hyperinflammatory condition, called multisystem inflammatory syndrome (MIS-C), was described in children and adolescents. This syndrome that was first described in Europe in April, 2020, usually occurs 2-6 weeks after acute SARS-CoV-2 infection and can affect multiple organ systems (cardiac, gastrointestinal, hematological, dermatological, neurological, respiratory, renal systems) (e.g. Abrams et al., 2021). 
78 Because the information regarding COVID-19 in pediatric patients is still sparse, we consider

79 that it's important to analyze the characteristics of the children diagnosed with SARS-CoV-2

80 infection, confirmed in our hospital. Such an analysis is helpful in more than one direction: to

81 obtain a more accurate picture of the disease spectrum in this specific population, to investigate

82 different factors of prediction for a probable unfavorable evolution in specific groups, thus

83 allowing to monitor and treat them promptly, to early diagnose any potential infected child

84 which would allow to implement specific measure for transmission control.

85 To our knowledge, this is the first Romanian report that describes the characteristics of COVID-

8619 in pediatric patients.

87 Objectives

88 The purpose of this paper is to analyze the epidemiological and clinical characteristics of the 89 children presented to "Marie Curie" Emergency Children's Hospital, who were diagnosed with

90 SARS-CoV-2 infection. Due to the fact that information on pediatric patients is still limited, we

91 aim to highlight the epidemiological and clinical data regarding SARS-CoV-2 infection in

92 children and adolescents, to improve the understanding of the disease in this age group and 93 inform physicians during the ongoing COVID-19 pandemic.

\section{Materials \& Methods}

95 We conducted a retrospective, observational study, in "Marie Curie" Emergency Children's

96 Hospital, a tertiary, multidisciplinary hospital from Bucharest, Romania, regarding the

97 characteristics of the pediatric patients diagnosed with SARS-CoV-2 infection during a seven

98 months period (April $1^{\text {st }}, 2020$ - October $31^{\text {st }}, 2020$ ). The study was approved by the Ethics

99 Committee of our hospital (SPIAAM no. 39945/29.10.2020) and we received written informed

100 consent from participants in our study.

101 Between April 1st, 2020-October 31 st, 2020, patients aged 0-18 years who presented to "Marie

102 Curie" Emergency Children's Hospital were tested for SARS-C0V-2 infection, using real-time

103 reverse transcription polymerase chain reaction (RT-PCR). The samples of nasopharyngeal

104 swabs were collected in our hospital and RT-PCR was performed in external laboratories.

105 According to the hospital protocol, all the patients who were admitted, both with suspicion of

106 SARS-CoV-2 infection and those without suspicion but who had other non-COVID-19

107 associated health problems for which they sought medical treatment, were tested for SARS-CoV-

1082 infection. SARS-CoV-2 infection suspected patients who needed inpatient care were isolated in

109 designated wards and, after the tests results were obtained, they were either relocated in the other

110 wards from the hospital (those with negative results) or they were transferred in COVID-19

111 designated hospitals (those with positive results). The patients with symptoms compatible with

112 SARS-CoV-2 infection, who presented to the emergency room, but who didn't have criteria for

113 inpatient treatment, were also tested and were given indication to remain at home until the test

114 result was available; those with positive results were informed and given further

115 recommendations according to the national regulations. The non-suspect patients who were

116 admitted for other health problems, were also passively screened for SARS-CoV-2 and those

117 who were found positive, were transferred in COVID-19 hospitals. 
118 The suspicion of SARS-CoV-2 infection was established based on National Methodology of

119 Surveillance for the Acute Respiratory Syndrome with the novel coronavirus (COVID-19),

120 which was available from march 2020 and updated regularly (e.g. CNSCBT, 2020).

121

122

123

124

125

126

127

128

129

130

131

132

133

134

135

136

137

138

139

140

141

142

143

144

145

146

147

148

149

150

151

152

153

154

155

156

The suspect cases were evaluated for SARS-CoV-2 infection, according to the methodology that was in place at the time of their presentation. Over the last 7 months, the definition of the suspect case was updated and recommendations for testing prioritization were established. Initially, the suspect case was defined as:1) Patient with acute respiratory infection (sudden onset of at least one of the symptoms: cough, fever, shortness of breath without other explanation) and history of travel/stay in a country/region with community transmission in the last 14 days prior to the onset of the symptoms; 2) Patient with acute respiratory infection and who came in close contact with a COVID-19 confirmed case in the last 14 days prior to the onset of the symptoms; 3) Patient with severe acute respiratory infection (fever and cough and shortness of breath) without other explanation for these symptoms and who needs inpatient care. The present definition of the suspect case includes:1) Any person with sudden onset of fever and cough or 2) Any person with sudden onset of at least 3 symptoms from: fever, cough, fatigue, headache, myalgia, odynophagia, rhinorrhea, shortness of breath, lack of appetite/nausea/vomiting, diarrhea, altered mental status, recent onset of anosmia or ageusia, in the absence of other explanation, or 3) Any person with pneumonia/bronchopneumonia with or without pleural effusion, or 4) Patient with severe acute respiratory infection (fever and cough and shortness of breath) without other explanation for his symptoms and who needs inpatient care; 5) For children younger than 16 years, SARS-CoV-2 infection can be suspected in case of digestive symptoms (vomiting, diarrhea) that are not associated with their diet.

The diagnosis of SARS-CoV-2 infection was confirmed based on National Methodology of Surveillance for the Acute Respiratory Syndrome with the novel coronavirus (COVID-19): positive RT-PCR, regardless of the presence of clinical signs and symptoms (e.g. CNSCBT, 2020). Other investigations were also performed according to the clinical picture of the patient and to the recommendation of the attending physician: chest $\mathrm{X}$-ray, hematological, $\mathrm{C}$ reactive protein, procalcitonine, liver enzymes, kidney panel.

The disease severity was defined, according to the national regulations of the Romanian Ministry of Health, as follows: asymptomatic ( patient with positive PCR-SARS-CoV-2 test and with no signs or symptoms of disease); mild (uncomplicated upper respiratory tract viral infection [e.g., fever, cough, sore throat, malaise, headache, muscle pain] without shortness of breath, dyspnea, or abnormal chest imaging); moderate (clinical and radiological signs of non-severe pneumonia and $\mathrm{SaO} 2>90 \%$ in room air), severe (e.g., severe pneumonia, hypoxia, dyspnea, tachypnea requiring hospitalization); and critical (e.g., severe pneumonia, acute respiratory distress syndrome, septic shock, and/or multiple organ dysfunction requiring hospitalization in intensive care).

The hospital's Department for Prevention of Healthcare Associated Infections recorded all the epidemiologic and clinical data of the SARS-CoV-2 positive patients. We retrospectively

Peer) reviewing PDF | (2021:02:58233:1:1:NEW 5 May 2021) 
157 analyzed the data from the epidemiological survey records, including: demographics, medical

158 history and underlying diseases, epidemiological history, laboratory tests, radiological findings.

159 Statistical analysis

160 Descriptive statistics were determined using SPSS software (version 25, IBM). Statistical

161 analysis of the data was performed to compare variables, as appropriate. Categorical variables

162 are presented as number and frequency rate. Continuous variables are presented as median and

163 interquartile range. Nonparametric tests were applied to compare independent samples.

164 Nonparametric tests for independent samples were used to compare the medians of the two

165 groups of patients regarding the median values of leukocytes, lymphocytes, neutrophils, platelets

166 and $\mathrm{C}$ reactive protein. The statistical significance was assessed by calculating statistical

167 significance threshold ( $\mathrm{p}$ value). $\mathrm{P}$ was considered significant for value less than 0.05 .

\section{Results}

\section{Characteristics of the patients}

170 Patients' characteristics are presented in Table 1.

171 Insert here table 1

172 Between April 1, 2020-October 31, 2020, 19619 patients aged 0-18 years were seen in our

173 hospital. RT-PCR for SARS-CoV-2 was performed in 7902 (40.28\%).

174172 patients were confirmed with SARS-CoV-2 infection, representing $2.18 \%$ of the total 7902

175 RT-PCR tests.

17679 (45.93\%) female patients and 93 (54.07\%) male patients were identified, with sex ratio males

177 per females of 1.18 .

178 The number of the patients with positive RT-PCR-SARS-CoV-2 tests increased gradually from

179 month to month, throughout the studied time frame: 3 patients (1.74\%) in April, 4 patients in

180 May (2.32\%), 10 patients in June (5.81\%), 21 patients (12.21\%) in July, 31 patients in August

181 (18.02\%), 39 patients (22.67\%) in September and 64 patients (37.21\%) in October.

182 Median age was 6.35 year ( 15 days-18 years). The distribution by age groups is detailed in Table 1831.

184 In 47 cases $(27.32 \%)$ we found a history of exposure to an identified source of infection: 37 185 patients (78.72\%) were exposed to a source from their family, 8 patients $(17.02 \%)$ had exposure 186 in the community, 1 patient $(2.13 \%)$ was in institutionalized care where a cluster of SARS-Cov-2 187 was identified and 1 patient $(2.13 \%)$ was transported to our hospital for hemodialysis and he 188 traveled in the same ambulance with a SARS-CoV-2 positive patient. Regarding the patients 189 with family exposure, at the time of the epidemiological inquiry, in 35 cases we identified 190 exposure to 1 family member (mother or father in 30 cases, brother in 1 case, grandmother in 2 191 cases and for 2 brothers, the source of the infection was their aunt), in 1 case the child had been 192 exposed to both his SARS-CoV-2 confirmed parents and 1 child had exposure to 3 family 193 members (mother, father and grandfather). Out of the 172 patients, 3 pairs of two brothers came 194 from the same families. Among the 47 patients with identified source, 6 patients didn't have any 195 symptoms compatible with SARS-CoV-2 infection. 
196

197

198

199

200

201

202

203

204

205

206

207

208

209

210

211

212

213

214

215

216

217

218

219

220

221

222

223

224

225

226

227

228

229

230

231

232

233

234

235

In 28 (16.28\%) patients we identified at least one previous medical condition: obesity ( 2 patients), neurological or neurosurgical conditions (i.e.,epilepsy, congenital hydrocephalus -8 patients), oncological or hematological conditions (i.e., acute or chronic lymphocytic leukemia, neuroblastoma -7 patients), nephrological conditions including chronic kidney disease (6 patients), diabetes mellitus type 1 (3 patients), cystic fibrosis (1 patient), asthma ( 1 patient), chronic orthopedic conditions ( 2 patients). Most of the patients had only underlying condition; however, in 5 cases we identified more than one previous medical conditions.

\section{Clinical characteristics}

Out of 172 SARS-CoV-2 positive patients, 30 (17.44\%) had no symptoms and $142(85.56 \%)$ were symptomatic. Clinical findings on presentation included at least one of: fever (112 patients; 78.87\%), cough (57 patients; 40.14\%), nasal congestion and rhinorrhea (34 patients; 23.94\%), headache (26 patients; 18.31\%), odynophagia and dysphagia (26 patients; $18.31 \%$ ), nausea (14 patients; 9.86\%), vomiting (21 patients; 14.79\%), diarrhea (21 patients; 14.79\%), abdominal pain (15 patients; $10.56 \%$ ), myalgia (19 patients; $13.38 \%$ ), anosmia/ageuzia (15 patients; $10.56 \%$ ), neurological symptoms (11 patients; $7.75 \%$ ) such as: irritability and restlessness ( 3 patients, one of them being a patient with a respiratory comorbidity), hypotonia (in a 12 years old female patient who was previously diagnosed with benign congenital hypotonia), generalized febrile seizures (one patient), pronounced drowsiness (2 patients), dizziness ( 3 patients), balance disorder (one patient), arthalgia ( 5 patients; $3.52 \%$ ), fatigue (5 patients; $3.52 \%$ ), apneic event ( 2 patients; $1.41 \%$ ) and nonspecific rash (1 patient; $0.7 \%$ ). None of the patients had hypoxia or dyspnea.

The comparison between the symptomatic patients with and without underlying conditions did not show any statistically significant differences between the two groups regarding any specific type of symptom (Table 2).

\section{Insert here table 2}

Most of the symptomatic patients had 3 symptoms (52 patients; $36.62 \%)$; 36 patients (25.35\%) had 2 symptoms; 23 patients $(16.2 \%)$ had 4 symptoms; 21 patients $(14.8 \%)$ had only one symptom; 9 patients $(6.33 \%)$ had 5 symptoms and in 1 patient $(0.7 \%)$ were identified 6 symptoms.

According to the patients' symptoms, we could identify three main groups of clinical phenotypes: a cluster of respiratory symptoms which included fever, cough, rhinorrhea, nasal congestion, a cluster of systemic enteric illness which included headache, myalgia, sore throat, vomiting, abdominal pain, diarrhea, fatigue, rash and a cluster of neurological symptoms which included irritability and restlessness, hypotonia, generalized febrile seizures, drowsiness, dizziness, balance disorder. Systemic enteric illness was the most frequent (48 patients, 33.8\%), followed by respiratory cluster (32 patients, $22.54 \%$ ) and neurological cluster was extremely rare (3 patients, 2.11\%). Fever alone was present in 18 patients $(12.68 \%)$ and in 41 cases $(28.87 \%)$ we found an overlap of the clusters: respiratory and systemic enteric illness (27 patients, $19.01 \%$ ), respiratory and neurological symptoms (4 patients, $2.82 \%$ ), neurological and systemic enteric illness ( 2 patients, $1.4 \%$ ) or all three clusters ( 8 patients, $5.63 \%$ ). We analyzed the 
236 distribution of the clinical clusters within the two groups of patients, with and without

237 comorbidities. Patients with comorbidities developed fever alone (3 patients), systemic enteric 238 illness (5 patients), respiratory illness ( 3 patients) or an association of respiratory, neurological 239 and systemic enteric illness (3 patients). Patients without comorbidities presented fever alone (15 240 patients), systemic enteric illness (43 patients), respiratory illness (29 patients), neurological

241 symptoms ( 3 patients) or an association of respiratory and systemic enteric illness (27 patients),

242 neurological and systemic enteric illness (2 patients) or respiratory, neurological and systemic

243 enteric illness (5 patients). When we compared the two groups regarding significant differences

244

245

246

247

248

249

250

251

252

253

254

255

256

257

258

259

260

261

262

263

264

265

266

267

268

269

270

271

272

273

274

275 from the clinical phenotypes point of view, we found that patients with comorbidities have a higher chance for developing an overlap of symptoms from all the clinical clusters $(p=0.03)$.

\section{Laboratory and radiological findings}

Laboratory and radiological examination were not performed in all the patients. In Table 3 are presented the data collected from the patients who underwent these evaluations.

\section{Insert here table 3}

Laboratory workup was performed according to the medical decision of the attending physician. Complete blood count was evaluated for 131 patients $(76.16 \%)$. Leukopenia was identified in 20 patients $(15.27 \%)$ and leukocytosis in 24 patients $(18.32 \%)$. However, 4 of the patients with elevated leukocytes had oncological or surgical pathologies which might have explained the hematological changes. Lymphopenia was noted in 34 cases (25.95\%), and in 11 cases $(8.4 \%)$ an elevated number of lymphocytes was observed. 20 patients (15.27\%) had neutrophilia and 16 patients $(12.21 \%)$ had decreased neutrophils count. Thrombocytopenia was identified in 2 patients $(1.53 \%)$, one of the patients having hematological underlying conditions as an explanation.

C-reactive protein was performed for 114 patients, in 46 (35.11\%) of them an elevated value being noticed.

Other tests (procalcitonine, aspartate aminotransferase and alanine aminotransferase, kidney function) were performed in a very low proportion of patients and could not be analyzed in order to draw any significant conclusion.

Chest X-ray was performed on initial evaluation for 50 patients (29.07\%). In half of them, there were no changes, while in 22 cases (44\%) showed peri and infrahilar mildly increased interstitial markings and in 3 cases (6\%) revealed alveolo-interstitial pneumonia (Table 3). Out of the 50 performed chest X-rays, 47 (94\%) were done for patients with symptoms: in 7 out of 14 patients with comorbidities ( 4 were abnormal and 3 were normal) and in 40 out 128 patients without comorbidities (21 were abnormal and 19 were normal). There was no statistical difference between patients with or without comorbidities regarding radiological changes $(p=1)$. In asymptomatic patients, chest X-ray was performed and found to be normal for 2 patients with and 1 patient without underlying diseases.

\section{Management}

Due to the fact that our hospital was not a COVID-19 hospital and according to the national regulations, all the patients admitted to our hospital, who were diagnosed with SARS-CoV-2 
276 infection and didn't have a pathology that required further inpatient treatment in our hospital, 277 were transferred for isolation, evaluation and management, to one of the COVID-19 designated 278 hospitals that have pediatric wards. This was the case for all the hospitalized patients evaluated 279 in this study.

$28068(39.53 \%$ ) patients (24 asymptomatic and 44 symptomatic) patients were admitted to the 281 hospital, requiring treatment for other medical condition (for asymptomatic patients) or inpatient 282 care for their symptoms (for symptomatic patients). The admitted patients awaiting for the tests 283 results were monitored and treated according to their symptoms and non-COVID-19 pathologies, 284 none of them requiring escalation of the treatment. 15 out of 24 asymptomatic patients confirmed 285 with SARS-CoV-2 infection were transferred once the condition for which they were admitted

286

287

288

289

290

291

292

293

294

295

296

297

298

299

300

301

302

303

304

305

306

307

308

309

310

311

312

313

314

315 was resolved; 11 of them were children with comorbidities. 9 out of 24 asymptomatic patients were discharged and isolated at home. 35 out of 44 symptomatic patients were transferred once the test result was available and 9 were discharged before, due to the favorable evolution. 98 symptomatic patients, who were evaluated and tested for SARS-CoV-2 infection in the emergency room and who didn't require inpatient treatment, were discharged at home, with symptomatic treatment and isolation recommendations. All the patients who were discharged at home, once the test result was available, were notified and given further instructions according to the local regulations for COVID-19 patients.

\section{Discussion}

To our knowledge, this is the first report on pediatric COVID-19 patients in Romania, with data from children and adolescents who were seen or managed within a tertiary health-care institution.

Since the beginning of the SARS-CoV-2 pandemic, it was noted that the disease was less frequent in children and also that among the infected children, a vast majority is spared of severe complications of COVID-19. In our study, SARS-CoV-2 infection was confirmed in $2.18 \%$ of the pediatric patients who presented to our hospital, during a seven months period. A review by the Chinese Center for Disease Control (CDC) showed that less than $1 \%$ of cases occurred in children younger than 10 years and most of them had non-severe disease (e.g. Wu et al., 2020). In Italy, pediatric patients accounted for $1.8 \%$ of the total infections (e.g. Bellino et al., 2020), consistent with data from Spain (e.g. Tagarro, 2020). The same low rate was initially reported in United States, with only 2\% of the cases being reported in pediatric patients in April 2020 (e.g.

Bialek et al., 2020). However, as the time passed and United States became one of the nations with extremely high rates of infection, the rates of infected children increased. According to a joint report from the American Academy of Pediatrics (AAP) and the Children's Hospital Association (CHA), pediatric cases have risen from $2 \%$ of cumulative reported cases in April to $10.5 \%$ in September, 2020 (Sisk et al., 2020; AAP, 2020).

In our study, an uptrend of monthly confirmed cases was noticed. At the beginning of the pandemics, the lockdown measures controlled the spread of the disease among all age groups, including children and adolescents. As time has passed, and the measures were lowered, especially during the summer time breaks, we witnessed an increasing number of cases. 
316 Although we don't have clear public information in this respect, we might hypothesize that the 317 beginning of the school year could be another explanation. We may speculate that, in the context 318 of the rapid spread and the increasing rates of SARS-CoV-2 infections, we will also see more 319 and more cases in children, as the pandemic is ongoing. An interesting observation was made in 320 respect to the age distribution of the patients from our study compared to the national data. In our

321

322

323

324

325

326

327

328

329

330

331

332

333

334

335

336

337

338

339

340

341

342

343

344

345

346

347

348

349

350

351

352

353

354

355 study, children aged 0-9 years represented 104 (60.47\% of the study population), whereas children aged 10-18 years represented 68 (39.53\%). Conversely, at national level, children aged $0-9$ years represented $31.69 \%$ of the total pediatric cases and children aged $10-18$ years represented $68.31 \%$ (e.g.Sava, 2020b). This inverted proportion of age groups between cases reported at national level (both hospitalized and non-hospitalized cases) and cases from our hospital, may be due to the fact that although overall older children and adolescents are more frequently affected, parents of younger children seek medical help more often than those of older children. Also, children aged 1-4 years have closer contacts within children's collectivities and facial mask is not mandatory for this age group and even if it would be, small children could not comply with this rule, therefore being more exposed. Interestingly, $18.02 \%$ of the cases were in children aged 0-1 year, who probably were infected from their households and other caregivers. The transmission of SARS-CoV-2 infection from adults to children has been confirmed and attributed to high prevalence of the disease in children. Exposure to an identified source was identified in many SARS-CoV-2 infected children, in up to $90 \%$ of the evaluated cases in some studies (Zhang et al., 2020; Cao et al., 2020). In our study, a source of infection was identified in over a quarter of the cases, mostly in the household environment, children being infected by adult relatives, which may explain the number of cases identified in small children. We anticipate that with the increasing number of infected adult contacts, the number of pediatric infections will also increase concomitantly and more family clusters will be identified in the future.

Besides the low prevalence of the disease in children, the available data highlight the fact that most children exhibit mild, if any, illness caused by SARS-CoV-2. In our study, $17.44 \%$ of the patients with positive RT-PCR didn't have either symptoms, or radiological features of disease. Our observation is consistent with reports by other authors (e.g. Lu et al., 2020). A multicentre cohort study involving 82 participating health-care institutions across 25 European countries showed that $16 \%$ of the SARS-CoV-2 infected children were asymptomatic (e.g. Götzinger et al., 2020). Traditionally, patients with underlying conditions are considered high risk for severe infections. Most of severe and critical cases or deaths in COVID-19 children occurred in those with comorbidities, the same as in adult patients (e.g. Ludvigsson, 2020). Lu X. et al, in a study including 171 patients, reported 3 children with hydronephrosis, leukemia and intussusception, who required mechanical ventilation (e.g. Lu et al., 2020). Other authors also found a significantly increased risk of severe COVID-19 and COVID-19-associated mortality in children with comorbidities. A systematic review and meta-analysis by Tsankov et al. found that $5.1 \%$ of children with comorbidities presented severe COVID-19 compared to $0.2 \%$ of children without comorbidities and COVID-19-associated mortality was $1.5 \%$ in children with pre-existing 
356

357

358

359

360

361

362

363

364

365

366

367

368

369

370

371

372

373

374

375

376

377

378

379

380

381

382

383

384

385

386

387

388

389

390

391

392

393

394

395

conditions and $0.03 \%$ in children without comorbidities (e.g. Tsankov et al., 2021). Swann et al. noted that children with comorbidities were more likely to be admitted to critical care than those without comorbidities and comorbidities most commonly associated with critical care admission were prematurity, respiratory and cardiac comorbidities. Six patients died in the hospital, all of them being patients with severe comorbidities or illnesses ((e.g. Swann at al, 2020).

In our study, 28 (16.28\%) of the children infected with SARS-CoV-2 had underlying conditions and 5 of them had more than one comorbidity. Interestingly, in our study, the rate of comorbidities in asymptomatic patients was significantly higher than in symptomatic patients. In the same manner, we found a higher rate of patients with oncohematological comorbidities than in symptomatic group. This is consistent with other studies that noted that children with certain underlying conditions, such as cancer, who are infected with SARS-CoV-2 are not more vulnerable than other children and do not usually develop severe illness (Boulad et al., 2020; Choi et al., 2020). Other authors have also seen a low risk of severe COVID-19 in children with comorbidities. Brisca et al. focused on the evolution of 37 pediatric patients with comorbidities and COVID-19 and concluded that although 78\% were hospitalized, $81 \%$ had minimal or absent respiratory symptoms, only 2 required oxygen support and none of them needed mechanical ventilation or intensive care admission (Brisca $G$ et al., 2020). In symptomatic COVID-19 children, the most common described symptoms are fever, cough, gastrointestinal symptoms; headache and myalgia are also reported (Williams et al., 2020; Götzinger et al., 2020; Hoang et al., 2020). In our study, the most frequent symptom was pyrexia (temperature above $38^{\circ} \mathrm{C}$ ), followed by digestive symptoms (nausea, vomiting, diarrhea, abdominal pain), cough, nasal congestion and rhinorrhea, headache, odynophagia and dysphagia, myalgia. Anosmia, with or without ageusia were also recorded in $10 \%$ of our patients, which is lower than the rates described in adults or reported in children by other authors (e.g. Qiu et al., 2020). As it has been suggested, these dysfunctions may represent early or the only symptom of SARS-CoV-2 infection in both adults and children and they may help to identify oligosymptomatic or atypically symptomatic patients. However, these symptoms may be of little help, especially in small children, who might be unable to describe them. In our study, anosmia and ageusia were recognized by children above 6 years of age. Other symptoms were present in a smaller number of cases: other non-specific and non-severe neurological symptoms (restlessness and irritability, dizziness, drowsiness, febrile seizures, generalized hypotonia, balance disorder), arthralgia, fatigue, apneic event, nonspecific rash.

When we compared patients with underlying medical conditions with those without underlying medical conditions, in terms of any particular symptom that might be present in the first group, we didn't identify any statistically significant differences for any of the symptoms analyzed separately. Swann et al. pointed out three distinct clusters of clinical phenotypes: the most frequent was a cluster of systemic mucocutaneous-enteric illness (headache, myalgia, sore throat, vomiting, abdominal pain, diarrhea, fatigue, rash, lymphadenopathy, and conjunctivitis) followed by a cluster of upper and lower respiratory symptoms (cough, fever, shortness of breath, runny nose, lower chest wall indrawing, wheeze), and a rarer cluster of neurological symptoms 
396 (seizures, confusion) (e.g. Swann at al., 2020). We could also identify these clusters of 397 symptoms in our patients, but with some differences regarding the symptoms from each cluster. 398 Respiratory symptoms included fever, cough, rhinorrhea, nasal congestion; we didn't identify 399 lymphadenopathy and conjunctivitis in the second cluster; we included more symptoms in the 400 neurological cluster (irritability and restlessness, hypotonia, generalized febrile seizures, 401 drowsiness, dizziness, balance disorder). In our study, systemic enteric illness was also the most

402

403

404

405

406

407

408

409

410

411

412

413

414

415

416

417

418

419

420

421

422

423

424

425

426

427

428

429

430

431

432

433

434 frequent, followed by respiratory cluster and neurological cluster was extremely rare. We also found that patients with comorbidities have a higher chance for developing an overlap of symptoms from all the clinical clusters.

From the experience with COVID-19 adults, we have learnt that an elevated number of leukocytes and neutrophils, as well as a low lymphocytes count are associated with a severe evolution (e.g. Lippi and Plebani, 2020). Unlike adults, in children with COVID-19, a normal white blood cells count is usually present and lymphopenia is rarer, which may explain the milder form of disease in pediatric population (Liao et al., 2002; Castagnoli et al., 2020). When abnormalities of the leukocytes count were found, leukopenia was the most common (Patel, 2020; Meena et al., 2020). A low platelets count has been more frequent identified in critically ill children and has been associated with respiratory deterioration in children (Romani et al., 2020; Bhumbra et al., 2020). The findings in our study showed the same: most of the patients had a normal hematological profile and in the few cases in which "classical" markers of a possible unfavorable evolution where noted, they were not corelated with a more severe evolution. Also, when we compared the complete blood count for symptomatic against asymptomatic patients, we didn't find any significant differences, except for the monocytes count. Xiong et al. found that symptomatic COVID-19 infected children had a significantly higher monocytes count than asymptomatic patients (e.g. Xiong et al., 2020). Regarding this aspect, there aren't homogenous conclusions at this time. There are studies in adults that concluded that monocytes count was usually in normal range in COVID-19 patients, however it could be towards the lower range in severe patients (e.g. Cong-Ying et al., 2020). In other studies, no differences were found between non-severe and severe patients in terms of monocytes count (e.g. Qin et al., 2020), whilst other authors showed that COVID-19 patients had a higher monocytes count compared to healthy individuals, but still within the normal range (e.g. Kermali et al., 2020). Although imaging studies of children with known or suspected SARS-CoV-2 infection are not routinely recommended, they play an important role especially in pediatric patients with a moderate to severe COVID-19 in order to establish a baseline, to assess any complications related to specific underlying conditions, to monitor the disease progression or to evaluate the treatment response ( $A C R, 2020$; Foust et al., 2020). Chest imaging findings in children with COVID-19 are frequently normal or mild. However, studies are describing heterogenous aspects of imaging studies in SARS-CoV-2 infected children. Lower lobes are commonly affected, but the upper or middle lobe involvement, as well as diffuse or multifocal disease is described. Although the most common described pattern was ground-glass opacity, patchy consolidations or 
435 a halo sign of ground-glass opacification around areas of consolidation were also found (e.g.

436 Shelmerdine et al., 2020).

437 In our study, 50 patients (29.07\%) underwent Chest X-ray on initial evaluation. We found that

438 half of the symptomatic patients had signs of non-severe pneumonia. None of them had the 439 classical ground-glass pattern. Chest X-ray was also evaluated in 3 asymptomatic children, and it

440 was unremarkable, although even in asymptomatic patients' radiological findings might be found

441 (e.g. Chan et al., 2020). We found no statistical difference between patients with or without

442 comorbidities regarding radiological changes.

443 Based on the presence or absence of the symptoms, the amplitude of the symptoms and

444 radiological signs, we could conclude that patients who presented to our hospital for evaluation

445 and management, exhibited either asymptomatic infection (17.44\%), mild disease (68.02\%), or

446 moderate disease (1.04\%). These findings mirror one particularity of the global pandemic caused

447 by SARS-CoV-2, namely that unlike many respiratory viruses, pediatric patients have been

448 relatively spared by severe illness. The explanation might come from several directions: fewer

449 underlying conditions, the differences in their immune response to the virus and lower

450

451

452

453

454

455

456

457

458

459

460

461

462

463

464

465

466

467

468

469

470

471

472

473

474 predisposition to proinflammatory states, differential expression of ACE2 in this group of patients, which may attenuate viral entry, ongoing viral replication and subsequent inflammation, hypoxia and tissue injury (e.g. Williams et al., 2020).

In our study, about $60 \%$ of the patients didn't require inpatient treatment and almost $40 \%$ of the patients were admitted. About one third of the admitted patients were asymptomatic, being admitted for the treatment of another underlying condition, either acute or chronic; they underwent the screening imposed by our internal regulations and tested positive for SARS-CoV2 infection. About two thirds of the patients were symptomatic. None of the admitted patients required admission to the ICU. According to our national regulations, once the SARS-CoV-2 infection was confirmed, the patients were transferred to COVID-19 designated hospitals. To our knowledge, none of these patients had a further unfavorable or complicated evolution, including those with predisposing factors for severe infections. Our findings are concurrent with other authors, as severe acute phase of infection requiring admission to ICU is rare in children. At Wuhan Children's Hospital, only 1.8\% out of 171 COVID-19 children required ICU admission (e.g. Lu et al., 2020). Tagarro et al. found that although a high proportion of children required hospitalization (61\%), only $9.8 \%$ of the them required admission to ICU (e.g. Tagarro et al., 2020). In North America, most of SARS-CoV-2 infections in children, did not required hospitalization and those requiring ICU admission frequently had complex underlying conditions that weighted towards the need of ICU (Pathak et al., 2020; Andre et al., 2020; Garg et al., 2020). The 25 European countries multicenter cohort study regarding COVID-19 in children and adolescents, highlighted that $62 \%$ of the patients were admitted to hospital, $8 \%$ of them required ICU admission and 4\% needed mechanical ventilation (e.g. Götzinger et al., 2020).

There are limitations of this study. Firstly, the recorded data were non-homogenous (not all the patients underwent chest-Xray, a unitary laboratory tests panel was not applied), the laboratory and imaging tests were ordered and performed according to the clinical judgment of the 
475 attending physician, without involvement from the study team, which only recorded the available 476 data. Therefore, a decision was made not to collect detailed data on all laboratory parameters 477 when they were available in a very small number. Also, we consider that the very different sizes 478 of the two compared groups (with and without underlying conditions) represented an obstacle for 479 drawing more significant clinical conclusions. Another limitation regards the fact that we could 480 not directly evaluate the short and especially the long-term evolution of the patients, which

481

482

483

484

485

486

487

488

489

490

491

492

493

494

495

496

497

498

499

500

501

502

503

504

505

506

507

508

509

510

511

512

513

514 remains to be seen. In the future, we consider this to be an important step in the management of children affected by SARS-CoV-2 infection. In contrast with adults, were there are preliminary concerning data regarding the longer-term respiratory, cardiac and neurological sequelae, in children, aside the sequelae from the multisystem inflammatory syndrome associated with SARS-CoV-2, there are still little outcome data beyond acute infection.

These days we are experiencing a rising number of cases in Romania, as well as in many other countries. Therefore, we are expecting to see an increasing rate of SARS-CoV-2 infection in children also, and it is important to keep monitoring the characteristics of the disease, its evolution, possible complications and sequelae in the pediatric patients, because with the pandemic progression, the clinical picture in children might change in the future.

\section{Conclusions}

Our results confirm less severe SARS-CoV-2 infection in pediatric patients than in adults. The results from our study showed that patients who presented to our hospital exhibited asymptomatic, mild and moderate illness due to infection with SARS-CoV-2, including the group of children with who are classically considered high risk patients for severe disease, such as children with cancer, cystic fibrosis, immunosuppression and other important comorbidities.

\section{References}

Abrams JY, Oster ME, Godfred-Cato SE, Bryant B, Datta SD, Campbell AP, Leung JW, Tsang CA, Pierce TJ, Kennedy JL, Hammett TA, Belay ED. 2021. Factors linked to severe outcomes in multisystem inflammatory syndrome in children (MIS-C) in the USA: a retrospective surveillance study. Lancet Child Adolesc Health 5: 323-331

DOI:10.1016/S2352-4642(21)00050-X.

American Academy of Pediatrics (AAP). 2020. Children and COVID-19: State Data Report. A joint report from the American Academy of Pediatrics and the Children's Hospital Association. https://services.aap.org/en/pages/2019-novel-coronavirus-covid-19infections/children-and-covid-19-state-level-data-report/ (Accessed November 3,2020).

American College of Radiology. ACR Recommendations for the use of Chest Radiography and Chest Computed Tomography (CT) for Susptected COVID-19 Infection. 2020. https://www.acr.org/Advocacy-and-Economics/ACR-PositionStatements/Recommendations-for-Chest-Radiography-and-CT-for-Suspected-COVID19Infection. (Accessed November 3, 2020).

Analiza rapida a cazurilor confirmate de infectie cu coronavirus Covid 19 Romania, 26 februarie - 18 martie 2020 (ora 18:00) [Rapid analysis of Romanian COVID-19 confirmed cases, February 26 - March 21], 2020. http://www.cnscbt.ro/index.php/analiza-cazuri-confirmate- 
515

516

517

518

519

520

521

522

523

524

525

526

527

528

529

530

531

532

533

534

535

536

537

538

539

540

541

542

543

544

545

546

547

548

549

550

551

552

553

554

covid19/1539-analiza-cazuri-confirmate-261-pana-la-18-03-2020/file (accessed October $31,2020)$.

Andre N, Rouger-Gaudichon J, Brethon B, Phulpin A, Thébault É, Pertuisel S, Gandemer V. 2020. COVID-19 in pediatric oncology from French pediatric oncology and hematology centers: high risk of severe forms? Pediatric Blood \& Cancer 67:e28392 DOI:10.1002/pbc.28392.

Bellino S, Punzo O, Rota MC, Manso MD, Urdiales AM, Adrianou X, Fabiani M, Boros S, Vescio F, Riccardo F, Bella A, Filia A, Rezza G, Villani A, Pezzotti P. 2020. COVID-19 Disease Severity Risk Factors for Pediatric Patients in Italy. Pediatrics 146(4):e2020009399 DOI: 10.1542/peds.2020-009399.

Bhumbra S, Malin S, Kirkpatrick L, Khaitan A, John CC, Rowan CM, Enane LA. 2020. Clinical Features of Critical Coronavirus Disease 2019 in Children. Pediatric Critical Care Medicine 21(10):e948-e953 DOI:10.1097/PCC.0000000000002511.

Bialek S, Gierke R, Hughes H, McNamara LA,Pilishvili T, Tami Skoff T. 2020. Coronavirus disease 2019 in children - United States, February 12-April 2, 2020. MMWR Morbidity and Mortality Weekly Report 69(14): 422-426 DOI:10.15585/mmwr.mm6914e4.

Boulad F, Kamboj M, Bouvier N, Mauguen A, Kung AL. 2020. COVID-19 in Children With Cancer in New York City. JAMA Oncology 6(9):1459-1460 DOI:10.1001/jamaoncol.2020.2028.

Brisca G, Mariani M, Pirlo D, Romanengo M, Castagnola E, Piccotti E, Moscatelli A. 2021. Clinical course of COVID-19 in children with pre-existing medical conditions. Acta Paediatrica 110:1291-1292 DOI:10.1111/apa.15730.

Cao Q, Chen YC, Chen CL, Chiu CH. 2020. SARS-CoV-2 infection in children: Transmission dynamics and clinical characteristics. Journal of the Formosan Medical Association 119(3):670-673 DOI:10.1016/j.jfma.2020.02.009.

Castagnoli R, Votto M, Licari A, Brambilla I, Bruno R, Perlini S, Rovida F, Baldanti F, Marseglia GL. 2020. Severe acute respiratory syndrome coronavirus 2 (SARS-CoV-2) infection in children and adolescents: a systematic review. JAMA Pediatrics 174(9):882889 DOI:10.1001/jamapediatrics.2020.1467.

Chan JF-W, Yuan S, Kok K-H, Kai-Wang To K, Chu H, Yang J, Xing F, Liu J, Yip CC-Y, Poon RW-S, Tsoi H-W, Lo SK-F, Chan K-H, Poon VK-M, Chan W-M, Ip JD, Cai JP, Cheng VC-C, Chen H, Hui CK-M, Yuen K-Y. 2020. A familial cluster of pneumonia associated with the 2019 novel coronavirus indicating person-to-person transmission: a study of a family cluster. The Lancet 395(10223):514-523 DOI:10.1016/S0140-6736(20)30154-9.

Choi SH, Kim HW, Kang JM, Kim DH, Cho EY. 2020. Epidemiology and clinical features of coronavirus disease 2019 in children. Clinicaland Experimental Pediatrics 63(4):125-132 DOI:10.3345/cep.2020.00535.

CNSCBT. 2020. National methodology of surveillance for the acute respiratory syndrome with the novel coronavirus (COVID-19). http://www.cnscbt.ro/index.php/informatii-pentrupersonalul-medico-sanitar?limit=20\&limitstart=40 (Accesed, October 31, 2020) 
555 Cong-Ying S, Jia X, Jian Q, Yuan-Qiang L. 2020. COVID-19 early warning score: a multi-

556

557

558

559

560

561

562

563

564

565

566

567

568

569

570

571

572

573

574

575

576

577

578

579

580

581

582

583

584

585

586

587

588

589

590

591

592 parameter screening tool to identify highly suspected patients. MedXRiv DOI:10.1101/2020.03.05.20031906.

Foust AM, Phillips GS, Chu WC, Daltro P, Das KM, Garcia-Peňa, Kilborn T, Winant A, Lee EY. 2020. International expert consensus statement on chest imaging in pediatric COVID-19 patient management: imaging study reporting and imaging study recommendations. Radiology: Cardiothoracic Imaging 2(2):e200214 DOI:10.1148/ryct.2020200214.

Garg S, Kim L, Whitaker M, O’Halloran A, Cummings C, Holstein R, Prill M, Chaj SJ, Kirley PD, Alden NB, Kawasaki B, Yousey-Hindes K. ..., Fry A. 2020. Hospitalization rates and characteristics of patients hospitalized with laboratory-confirmed coronavirus disease 2019 - COVID-NET, 14 States, March 1-30, 2020. Morbidity and Mortality Weekly Report 69(15):458-464 DOI:10.15585/mmwr.mm6915e3.

Götzinger F, Santiago-García B, Noguera-Julián A, Lanaspa L, Lancella L, Calò Carducci F, Gabrovska N, Velizarova S, Prunk P, Osterman V, Krivec U, Lo Vecchio A, Shingadia D, Soriano-Arandes A, Melendo S, Lanari M, Pierantoni L, Wagner N. ... Riordan A. 2020. COVID-19 in children and adolescents in Europe: a multinational, multicentre cohort study. The Lancet Child \& Adolescent Health 4(9):653-661 DOI:10.1016/S23524642(20)30177-2.

Hoang A, Chorath K, Moreira A, Evans M, Burmeister-Morton F, Burmeister F, Naqvi R, Petershack M, Moreira A. 2020. COVID-19 in 7780 pediatric patients: A systematic review. EClinicalMedicine 24:100433doi:10.1016/j.eclinm.2020.100433.

Kermali M, Khalsa RK, Pillai K, Ismail Z, Harky A. 2020. The role of biomarkers in diagnosis of COVID-19 - A systematic review. Life Sciences 254:117788 DOI:10.1016/j.lfs.2020.117788.

LiaoYC, LiangWG,Chen FW, Hsu JH, Yang JJ, Chang MS. 2002. IL-19 inducesproduction of IL-6 and TNF-alpha and results in cell apoptosis through TNF-alpha. Journal of Immunology 169:4288-4297 DOI:10.4049/jimmunol.169.8.4288.

Lippi G, Plebani M. 2020. Laboratory abnormalities in patients with COVID-2019 infection. Clinical Chemistry and Laboratory Medicine 58:1131-1134 DOI:10.1515/cclm-20200198.

Livingston E, Bucher K. 2020. Coronavirus Disease 2019 (COVID-19) in Italy. JAMA. 323(14):1335 DOI:10.1001/jama.2020.4344.

Lu X, Zhang L, Du H, Zhang J, Li YY, Qu J, Zhang W, Wang Y, Bao S, Li Y, Wu C, Liu H, Liu D. ...Xu S, Wong GWK. 2020. SARS-CoV-2 infection in children. $N$ Engl J Med 382:1663-1665 DOI:10.1056/NEJMc2005073.

Ludvigsson JF. 2020. Systematic review of COVID-19 in children shows milder cases and a better prognosis than adults. Acta Paediatrica 109(6):1088-1095 DOI: 10.1111/apa.15270. 
593 Meena J, Yadav J, Saini L, Yadav A, Kumar J. 2020. Clinical Features and Outcome of SARS-

594

595

596

597

598

599

600

601

602

603

604

605

606

607

608

609

610

611

612

613

614

615

616

617

618

619

620

621

622

623

624

625

626

627

628

629

630

631

632 CoV-2 Infection in Children: A Systematic Review and Meta-analysis. Indian Pediatrics 57(9):820-826 DOI:10.1007/s13312-020-1961-0.

Patel NA. 2020. Pediatric COVID-19: systematic review of the literature. American Journal of Otolaryngology 41(5):102573 DOI:10.1016/j.amjoto.2020.102573.

Pathak EB, Salemi JL, Sobers N, Menard J, Hambleton IR. 2020. COVID-19 in children in the United States: intensive care admissions, estimated total infected, and projected numbers of severe pediatric cases in 2020. Journal of Public Health Management and Practice 26(4):325-333 DOI:10.1097/PHH.0000000000001190.

Qin C, Zhou L, Hu Z, Zhang S, Yang S, Tao Y, Xie C, Ma K, Shang K, Wang W, Tian DS. 2020. Dysregulation of Immune Response in Patients With Coronavirus 2019 (COVID-19) in Wuhan, China. Clinical Infectious Diseases 71(15):762-768 DOI:10.1093/cid/ciaa248.

Qiu C, Cui C, Hautefort C, Haehner A, Zhao J, Yao Q, Zeng H, Nisenbaum EJ, Liu L, Zhao Y, Zhang D, Levine CG. Cejas I, Dai Q, Zeng M, Zeng M, Herman P, Jourdaine C. ... Lu H. 2020. Olfactory and Gustatory Dysfunction as an Early Identifier of COVID-19 in Adults and Children: An International Multicenter Study. Otolaryngology-Head and Neck Surgery 163(4):714-721 DOI:10.1177/0194599820934376.

Riphagen S, Gomez X, Gonzalez-Martinez C, Wilkinson N, Theocharis P. 2020. Hyperinflammatory shock in children during COVID-19 pandemic. The Lancet 395(10237):1607-1608 DOI:10.1016/S0140-6736(20)31094-1.

Romani L, Chiurchiù S, Santilli V, Bernardi S, Lombardi MH, Scarselli A, Villani A, Ciofi Degli Atti ML, Campana A, D'Argenio P. 2020. COVID-19 in Italian paediatric patients: The experience of a tertiary children's hospital [published online ahead of print, $2020 \mathrm{Jul} 8$ ]. Acta Paediatrica 109(11):2311-2312 DOI:10.1111/apa.15465.

Sava JA. 2020a. Number of people infected with coronavirus (COVID-19) in Romania as of November 1, 2020, by age group. Statistica https://www.statista.com/statistics/1104592/romania-covid-19-infections-by-age-group/ (accesed November 1, 2020).

Sava JA. 2020b. Number of people infected with coronavirus (COVID-19) in Romania, by age group. Statista https://www.statista.com/statistics/1104592/romania-covid-19-infectionsby-age-group/ (Accesed November 3, 2020).

Shelmerdine SC, Lovrenski J, Caro-Domínguez P, Toso S. 2020. Coronavirus disease 2019 (COVID-19) in children: a systematic review of imaging findings. Pediatric Radiology 50:1217-1230 doi:10.1007/s00247-020-04726-w.

Sisk B, Cull B, Harris M, Rothenburger A, Olson L. 2020. National trends of cases of COVID19 in children Based on US State Health Department data. Pediatrics 146(6) e2020027425; DOI:10.1542/peds.2020-027425 (Accesed November 3, 2020).

Swann OV, Holden KA, Turtle L, Pollok L, Fairfield CJ, Drake TM, Seth S, Egan C, Hardwick HE, Halpin S, Girvan M, Donohue C, Pritchard M, Patel LB, Ladhani S, Sigfrid L, Sinha IP, Olliaro PL, Nguyen-Van-Tam JS, Horby PW, Merson L, Carson G, Dunning J, 
633

634

635

636

637

638

639

640

641

642

643

644

645

646

647

648

649

650

651

652

653

654

655

656

657

658

659

660

661

662

663

664

665

666

667

Openshaw PJM, Baillie JK, Harrison EM, Docherty AB, Semple MG. 2020. Clinical characteristics of children and young people admitted with COVID-19 in United Kingdom: prospective multicentre observational cohort study. BMJ 370: m3249

DOI:10.1136/bmj.m3249.

Tagarro A, Epalza C, Santos M, Sanz-Santaeufemia FJ, Otheo E, Moraleda C, Calvo C. 2020. Screening and Severity of Coronavirus Disease 2019 (COVID-19) in Children in Madrid, Spain [published online ahead of print, 2020 Apr 8]. JAMA Pediatrics. e201346 DOI:10.1001/jamapediatrics.2020.1346.

Tsankov BK, Allaire JM, Irvine MA, Lopez AA, Sauvé LJ, Vallance BA, Jacobson K. 2021. Severe COVID-19 Infection and Pediatric Comorbidities: A Systematic Review and MetaAnalysis. International Journal of Infectious Diseases 103:246-256 DOI:10.1016/j.ijid.2020.11.163

Williams PCM, Howard-Jones AR, Hsu P, Palasanthiran, P, Gray PE, Mcmullan BJ, Britton P, Adamw. Bartlett AW. 2020. SARS-CoV-2 in children: spectrum of disease, transmission and immunopathological underpinnings. Pathology 52(7),801-808

DOI:10.1016/j.pathol.2020.08.001.

World Health Organization (WHO), 2020a. Weekly Operational Update on COVID-19 30 October 2020. https://www.who.int/publications/m/item/weekly-operational-update---30october-2020 (accessed October 31, 2020).

World Health Organization (WHO), 2020b. Novel coronavirus (2019-nCoV) situation report 5. https:/www.who.int/docs/default-source/coronaviruse/situation-reports/20200125-sitrep-52019-ncov.pdf?sfvrsn=429b143d_8 (accessed October 31,2020).

World Health Organization (WHO), 2020c. Coronavirus Disease (COVID-19) Dashboard. https://covid19.who.int/ (accessed October 31, 2020).

Wu Z, McGoogan JM. 2020. Characteristics of and Important Lessons from the Coronavirus Disease 2019 (COVID-19) Outbreak in China: Summary of a Report of 72314 Cases from the Chinese Center for Disease Control and Prevention. JAMA 323(13):1239-1242. DOI:10.1001/jama.2020.2648.

Xiong X, Chua GT, Chi S, Kwan MYW, Wong WHS, Zhou A, Shek CC, Tung KTS, Qin H, Wong RS, Li X, Chen P, ... Ip P. 2020. Haematological and immunological data of Chinese children infected with coronavirus disease 2019. Data in Brief 31:105953 DOI:10.1016/j.dib.2020.105953.

Zhang C, Gu J, Chen Q, Deng N, Li J, Huang L, Zhou X.2020. Clinical and epidemiological characteristics of pediatric SARS-CoV-2 infections in China: A multicenter case series. PLoS Medicine 17(6):e1003130 DOI:10.1371/journal.pmed.1003130. 


\section{Table 1 (on next page)}

Characteristics of the patients

Nonparametric tests were applied to compare independent samples $p<0.05$ 


\begin{tabular}{|c|c|c|c|c|c|}
\hline Parameter & Indicators & $\begin{array}{l}\text { Total } \\
\mathrm{N}=172\end{array}$ & $\begin{array}{l}\text { With } \\
\text { symptoms } \\
\mathrm{N}=142 \\
(85.56 \%)\end{array}$ & \begin{tabular}{|l|} 
Without \\
symptoms \\
$\mathrm{N}=30$ \\
$(17.44 \%)$
\end{tabular} & $p$ \\
\hline \multirow[t]{2}{*}{ Gender } & Female & $79(45.93 \%)$ & $65(45.78 \%)$ & $14(46.66 \%)$ & 1 \\
\hline & Male & $93(54.07 \%)$ & $77(54.22 \%)$ & $16(53.33 \%)$ & 1 \\
\hline \multirow[t]{6}{*}{$\begin{array}{l}\text { Age } \\
\text { distribution }\end{array}$} & & $\begin{array}{l}15 \text { days- } 18 \\
\text { years } \\
\text { (median } 6.35 \text { ) }\end{array}$ & $\begin{array}{l}15 \text { days-18 } \\
\text { years } \\
\text { (median } 7)\end{array}$ & $\begin{array}{l}5 \text { months-18 } \\
\text { years } \\
\text { (median } 6.15 \text { ) }\end{array}$ & 0.84 \\
\hline & $0-1$ years & $31(18.02 \%)$ & $28(19.72 \%)$ & $3(10 \%)$ & 0.29 \\
\hline & $1-4$ years & $41(23.84 \%)$ & $31(21.83 \%)$ & $10(33.33 \%)$ & 0.23 \\
\hline & $5-9$ years & $32(18.6 \%)$ & $27(19.01 \%)$ & $5(16.67 \%)$ & 1 \\
\hline & 10-14 years & $29(16.86 \%)$ & $25(17.61 \%)$ & $4(13.33 \%)$ & 0.78 \\
\hline & $15-18$ years & $39(22.67 \%)$ & $31(21.83 \%)$ & $8(26.67 \%)$ & 0.63 \\
\hline \multirow{8}{*}{$\begin{array}{l}\text { Exposure to } \\
\text { identified } \\
\text { source }\end{array}$} & & $47(27.32 \%)$ & $41(28.87 \%)$ & $6(20 \%)$ & 0.2 \\
\hline & Family & $37(78.72 \%)$ & $32(78.05 \%)$ & $5(83.33 \%)$ & 1 \\
\hline & 1 family member & 35 & 30 & 5 & 0.62 \\
\hline & 2 family members & 1 & 1 & 0 & 1 \\
\hline & 3 family members & 1 & 1 & 0 & 1 \\
\hline & Community & $8(17.02 \%)$ & $8(19.51 \%)$ & $0(0 \%)$ & 0.57 \\
\hline & Institution of care & $1(2.13 \%)$ & $1(2.44 \%)$ & $0(0 \%)$ & 1 \\
\hline & $\begin{array}{l}\text { During transport to } \\
\text { hemodialysis }\end{array}$ & $1(2.13 \%)$ & $0(0 \%)$ & $1(16.66 \%)$ & 0.12 \\
\hline \multirow{8}{*}{$\begin{array}{l}\text { Underlying } \\
\text { medical } \\
\text { conditions }\end{array}$} & & $28(16.28 \%)$ & $14(9.86 \%)$ & $14(46.66 \%)$ & 0.00001 \\
\hline & Obesity & $2(1.16 \%)$ & $2(14.29 \%)$ & $0(0 \%)$ & 0.48 \\
\hline & Neurologic & $8(28.57 \%)$ & $5(35.71 \%)$ & $3(28.54 \%)$ & 0.1 \\
\hline & Oncologic/hematologic & $7(25 \%)$ & $1(7.14 \%)$ & $6(42.68 \%)$ & 0.0001 \\
\hline & Nephrologic & $6(21.23 \%)$ & $4(28.54 \%)$ & $2(14.28 \%)$ & 0.28 \\
\hline & Diabetes mellitus type 1 & $3(10.71 \%)$ & $1(7.14 \%)$ & $2(14.28 \%)$ & 0.07 \\
\hline & Respiratory & $2(7.14 \%)$ & $2(14.28 \%)$ & $0(0 \%)$ & 1 \\
\hline & $\begin{array}{l}\text { Chronic orthopaedic } \\
\text { condition }\end{array}$ & $2(7.14 \%)$ & $0(0 \%)$ & $2(12.28)$ & 0.02 \\
\hline \multirow{3}{*}{$\begin{array}{l}\text { Number of } \\
\text { underlying } \\
\text { conditions }\end{array}$} & 1 & $23(82.14 \%)$ & $11(78.57 \%)$ & $12(85.71 \%)$ & 1 \\
\hline & 2 & $4(14.29 \%)$ & $2(14.29 \%)$ & $2(14.29 \%)$ & 0.14 \\
\hline & 4 & $1(3.57 \%)$ & $1(7.14 \%)$ & $0(0 \%)$ & 1 \\
\hline
\end{tabular}




\section{Table 2 (on next page)}

Comparison of the symptoms between the group of patients with and without underlying conditions

* fever $\geq 38^{\circ} \mathrm{C}$; \# digestive symptoms: nausea, vomiting, diarrhea, abdominal pain; $\diamond$ neurological symptoms: restlessness and irritability, dizziness, drowsiness, febrile seizures, generalized hypotonia, balance disorder; Nonparametric tests were applied to compare independent samples $p<0.05$ 


\begin{tabular}{|l|l|l|l|}
\hline Symptoms & $\begin{array}{l}\text { Symptoms in patients with } \\
\text { underlying conditions } \\
(\mathrm{n}=14 \text { patients) }\end{array}$ & $\begin{array}{l}\text { Symptoms in patients without } \\
\text { underlying conditions } \\
\text { (n=128 patients) }\end{array}$ & $p$ \\
\hline Fever* & $10(71.43 \%)$ & $102(79.68 \%)$ & 0.49 \\
\hline Cough & $4(28.57 \%)$ & $53(41.40 \%)$ & 0.40 \\
\hline $\begin{array}{l}\text { Nasal congestion and } \\
\text { rhinorrhea }\end{array}$ & $2(14.29 \%)$ & $32(25 \%)$ & 0.36 \\
\hline Headache & $3(31.43 \%)$ & $23(17.97 \%)$ & 0.72 \\
\hline $\begin{array}{l}\text { Odynophagia and } \\
\text { dysphagia }\end{array}$ & $1(7.15 \%)$ & $25(19.53 \%)$ & 0.46 \\
\hline Digestive symptoms $\#$ & $5(35.71 \%)$ & $66(51.56 \%)$ & 0.18 \\
\hline Myalgia & $2(14.29 \%)$ & $16(12.5 \%)$ & 0.69 \\
\hline Anosmia/ageuzia & $2(14.29 \%)$ & $13(10.15 \%)$ & 0.64 \\
\hline $\begin{array}{l}\text { Neurological } \\
\text { symptoms }\end{array}$ & $2(14.29 \%)$ & $9(7.03 \%)$ & 0.29 \\
\hline Artharlgia & $2(14.29 \%)$ & $3(2.34 \%)$ & 0.07 \\
\hline Fatigue & $2(14.29 \%)$ & $4(3.12 \%)$ & 0.1 \\
\hline Apneic event & $0(0 \%)$ & $2(1.56 \%)$ & 1 \\
\hline Nonspecific rash & $0(0 \%)$ & $1(0.78 \%)$ & 1 \\
\hline
\end{tabular}


Table 3(on next page)

Laboratory and radiological characteristics

Nonparametric tests were applied to compare independent samples $p<0.05$ 


\begin{tabular}{|c|c|c|c|c|c|}
\hline Parameter & Indicators & $\begin{array}{l}\text { Total } \\
\mathrm{N}=172\end{array}$ & $\begin{array}{l}\text { With } \\
\text { symptoms } \\
\mathrm{N}=142 \\
(85.56 \%)\end{array}$ & $\begin{array}{l}\text { Without } \\
\text { symptoms } \\
\mathrm{N}=30 \\
(17.44 \%)\end{array}$ & $P$ \\
\hline \multirow[t]{4}{*}{ Chest X-ray } & & $50(29.07 \%)$ & $47(33.1 \%)$ & $3(10 \%)$ & \\
\hline & Normal & $25(50 \%)$ & $22(46.88 \%)$ & $3(100 \%)$ & 0.57 \\
\hline & $\begin{array}{l}\text { Bilateral peri and } \\
\text { infrahilar mildly } \\
\text { increased interstitial } \\
\text { marking }\end{array}$ & $22(44 \%)$ & $22(46.88 \%)$ & $0(0 \%)$ & 0.01 \\
\hline & $\begin{array}{l}\text { Unilateral alveolo- } \\
\text { interstitial pneumonia }\end{array}$ & $3(6 \%)$ & $3(6.38 \%)$ & $0(0 \%)$ & 1 \\
\hline \multirow{6}{*}{$\begin{array}{l}\text { Complete } \\
\text { blood count }\end{array}$} & & $131(76.16 \%)$ & $110(77.46 \%)$ & $21(70 \%)$ & \\
\hline & $\begin{array}{l}\text { Leukocytes }\left(4.5-10 \times 10^{9}\right. \\
\text { cells/L) }\end{array}$ & $\begin{array}{l}6860(1770- \\
103,000)\end{array}$ & $\begin{array}{l}6910 \quad(4600- \\
103,000)\end{array}$ & $\begin{array}{l}6710(1760- \\
14,640)\end{array}$ & 0.661 \\
\hline & $\begin{array}{l}\text { Lymphocytes }(1.5-6.5 \\
\mathrm{x} 10^{9} \text { cells/L) }\end{array}$ & $\begin{array}{l}2180 \quad(260- \\
11,640)\end{array}$ & \begin{tabular}{|l|}
$2190 \quad(460-$ \\
$11,640)$
\end{tabular} & $\begin{array}{l}1710 \quad(260- \\
84600\end{array}$ & 0.97 \\
\hline & $\begin{array}{l}\text { Neutrophils }\left(1.8-8 \times 10^{9}\right. \\
\text { cells/L) }\end{array}$ & $\begin{array}{l}3110 \quad(390- \\
88,870)\end{array}$ & \begin{tabular}{|l|}
$3100 \quad(390-$ \\
$88,870)$
\end{tabular} & $\begin{array}{l}3190 \quad(930- \\
12,050)\end{array}$ & 0.97 \\
\hline & $\begin{array}{l}\begin{array}{l}\text { Monocytes } \\
\text { cells/L) }\end{array} \\
\text { (0-1 } \times 10^{9} \\
\end{array}$ & $\begin{array}{l}850 \quad(100- \\
5700)\end{array}$ & \begin{tabular}{|ll}
900 & $(260-$ \\
$5700)$ & \\
\end{tabular} & $\begin{array}{l}440 \quad(100- \\
2860)\end{array}$ & 0.019 \\
\hline & $\begin{array}{l}\text { Platelets }\left(150-450 \times 10^{9}\right. \\
\text { cells/L) }\end{array}$ & $\begin{array}{l}252,000 \\
(37,000- \\
637,000) \\
\end{array}$ & $\begin{array}{l}254,000 \\
(124,000- \\
637,000) \\
\end{array}$ & $\begin{array}{l}252,000(27, \\
000- \\
511,000)\end{array}$ & 0.97 \\
\hline $\begin{array}{l}\mathrm{C} \text { reactive } \\
\text { protein }(<5 \\
\mathrm{mg} / \mathrm{l})\end{array}$ & & $\begin{array}{l}3.62(0.02- \\
305.2)\end{array}$ & $\begin{array}{l}3.77 \quad(0.02- \\
305.2)\end{array}$ & $\begin{array}{l}2.72(0.26- \\
71.88)\end{array}$ & 1 \\
\hline
\end{tabular}

